\title{
Evaluation of Surface Roughness and Material Removal Rate in End Milling of Complex Shape
}

\author{
Suha K. Shihab ${ }^{1, *}$, Ethar Mohamed Mahdi Mubarak ${ }^{2}$ \\ ${ }^{1}$ Department of Materials Engineering, Engineering College, Diyala University, Iraq \\ ${ }^{2}$ Mechanical Department, Institute of Technology, Middle Technical University, Iraq
}

Copyright $\bigcirc 2016$ by authors, all rights reserved. Authors agree that this article remains permanently open access under the terms of the Creative Commons Attribution License 4.0 International License

\begin{abstract}
In this work, an attempt has been made to analyze the influence of various machining input parameters of CNC end milling process viz. cutting speed, feed rate and depth of cut on machining output variables (surface roughness and material removal rate) during machining complex shape of copper. Three different levels of input parameters were planned as per Taguchi's $\mathrm{L}_{9}$ orthogonal array. The parameters are optimised from analysis of mean (ANOM). Analysis of variance (ANOVA) was employed to investigate the effect of machining parameters on the variables. Results of this study indicate that the depth of cut has the most significant effect on $\mathrm{R}_{\mathrm{a}}$ having percentage contribution of $71.06 \%$ followed by feed rate and cutting speed having percentage contribution of $23.22 \%$ and $2.12 \%$ respectively. For material removal rate, it is observed that the percentage contribution of feed rate is maximum i.e. $68.58 \%$ followed by depth of cut and cutting speed having percentage contribution of $22.13 \%$ and $7.52 \%$ respectively. Also, the results revealed that optimum combination of machining parameters which resulted in optimum value of the surface roughness is $A_{3} B_{1} C_{2}$ i.e. cutting speed of 6000 $\mathrm{rpm}$, feed rate of $500 \mathrm{~mm} /$ tooth and depth of Cut of $0.06 \mathrm{~mm}$. Similarly, optimum combination of machining parameters which resulted in optimum value of material removal rate is $A_{1}, B_{3} C_{3}$ where the values for cutting speed, feed rate and depth of cut are $2000 \mathrm{rpm}, 1500 \mathrm{~mm} /$ tooth and $0.08 \mathrm{~mm}$ respectively.
\end{abstract}

Keywords End Milling, Surface Roughness, Material Removal Rate, Copper, Optimization

\section{Introduction}

Surface roughness and material removal rate are two important aspects during machining which involve attention both from manufacturing as well as research and development point of view. In recent industry, one of the tendencies is to produce low cost, high quality products in short time [1]. The roughness of the machined surface is considered as the important aspect affecting on the quality of the product, function, and reliability [2-5]. On the other hand, the material removal rate is another important aspect in improving machining performance, effecting on the productivity and reduced lead times and cost [6]. It is very difficult for an operator to select optimum machining parameters to achieve best surface finish and higher productivity. Therefore, many researchers have focused on the effect of machining parameters and selection the optimum values of these parameters to determine best surface finish and highest value of material removal rate [1, 7].In this research an attempt has been made to produce complex shapes using vertical milling operation through end milling process. The specific objectives of the study are: to understand milling machine and various milling operations; to investigate the effect of various machining parameters on surface roughness and material removal rate; and to optimize the machining parameters. Experiments have been carried out according to Taguchi's $\mathrm{L}_{9}$ orthogonal array (OA) on a $\mathrm{CNC}$ vertical milling machine. The details of the procedure are discussed in the following sections.

\section{Materials}

In this research, a workpiece made of a copper with high purity $(99.9 \% \mathrm{Cu})$ was used. Pure copper is hard to machine due to high ductility, while machining the cutting force on the rake face of the tool increases too much which leads to an overall increase in the cutting forces. Pure copper finds its application in making the pipes that are used in heat exchangers and also in electrical applications such as switches and electrical boards that have features such as holes, slots and pockets which are produced by machining. . Many applications for electronic and manufacturing industry require microstructural stability and high temperature resistance materials, good mechanical properties, high electrical conductivity and corrosion resistance. For such applications, the most promising metal is copper because of its high electrical and thermal conductivity [8]. Table 1 shows the chemical composition of copper which was used in this research. High speed steel and cemented carbide tools were employed as the cutting tool material. The end milling operation was carried out by using end mill cutter and ball mill cutter $(8 \mathrm{~mm})$. 
Table 1. Chemical composition of copper

\begin{tabular}{|c|c|c|c|c|c|c|c|c|c|c|}
\hline Elements & Copper & Tin & Lead & Iron & Nickel & Manganese & Cobalt & Silver & Phosphorus & Zinc \\
\hline Composition \% & 99.90 & 0.024 & 0.004 & 0.002 & 0.002 & $<0.001$ & $<0.001$ & 0.001 & 0.040 & 0.017 \\
\hline
\end{tabular}

\section{Experimental Method}

From a bar, copper cube of $80 \mathrm{~mm}$ was cut by power hacksaw and face milling was carried out on vertical CNC milling machine using face milling cutter. Then, the experiments were carried out on vertical $\mathrm{CNC}$ milling machine by using different machining parameters of $\mathrm{L}_{9}$ orthogonal array. The machining parameters and their levels used in present study as shown in Table 2. Nine hemispherical shapes (Complex Shape geometry) were formed on nine faces of two cubes, 6 hemispheres on 6 faces of one cube and 3 on the other cube, using end milling cutter and for better surface finish, ball milling cutter of $8 \mathrm{~mm}$ was used. Each hemisphere has three different Radii $(24.75 \mathrm{~mm}$, $25 \mathrm{~mm}$ and $25.25 \mathrm{~mm}$ ) as shown in the Figure 1. Surface roughness values were measured by surface roughness tester (SURTEST SV-2100; make: Mitutoyo, Japan). During machining, the material removal rate was calculated against recorded "time of cut".

Table 2. Machining parameters and their levels

\begin{tabular}{|c|c|c|c|c|}
\hline Factors & Symbol & Level 1 & Level 2 & Level 3 \\
\hline Speed (rpm) & A & 2000 & 4000 & 6000 \\
\hline $\begin{array}{c}\text { Feed rate } \\
\text { (mm/tooth) }\end{array}$ & B & 500 & 1000 & 1500 \\
\hline $\begin{array}{c}\text { Depth of cut } \\
\text { (mm) }\end{array}$ & C & 0.04 & 0.06 & 0.08 \\
\hline
\end{tabular}

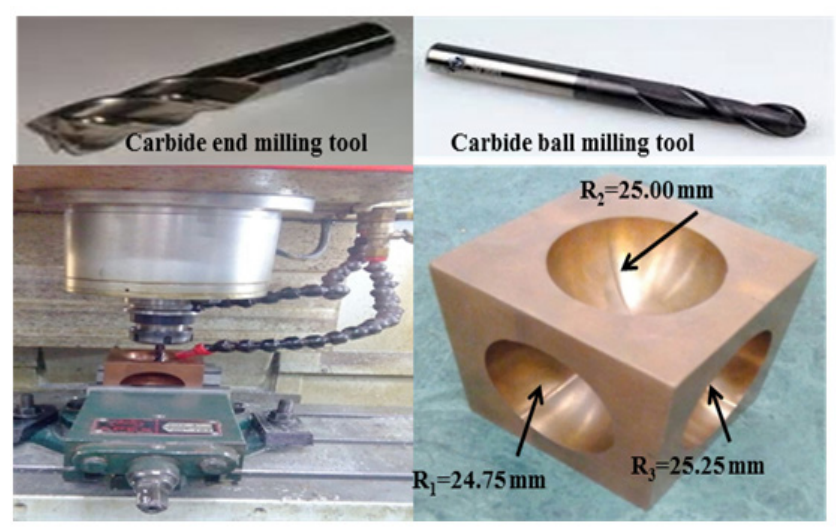

Figure 1. milling operation of copper cube

\section{Taguchi Design of Experiment}

In this study, experiments based on Taguchi $\mathrm{L}_{9}$ orthogonal array were performed to determine the best levels of the process parameters. The greatest advantages of the Taguchi method are to decrease the experimental time, to reduce the cost and to find out significant factors in a shorter time period $[9,10]$. Taguchi used the $\mathrm{S} / \mathrm{N}$ ratio as the quality characteristic of choice to analyze the data [11-13]. The methods for calculating the $\mathrm{S} / \mathrm{N}$ ratio are classified into three main categories, depending on whether the desired quality characteristics are smaller the better, larger the better or nominal the better. In the case of surface roughness, the smaller values are always considered and in case of material removal rate, the larger values are always considered. The Eq.1 and Eq. 2 were applied for calculating the $\mathrm{S} / \mathrm{N}$ ratio for smaller the better characteristics and larger the better characteristics respectively.

$$
\begin{aligned}
& \mathrm{S} / \mathrm{N}=-10 \log \frac{1}{n} \sum_{i=1}^{m} y_{i j}^{2} \\
& \mathrm{~S} / \mathrm{N}=-10 \log \frac{1}{n} \sum_{i=1}^{m} \frac{1}{y_{i j}^{2}}
\end{aligned}
$$

\section{Results and Discussion}

In this section, an ANOVA is conducted to analyze the experimental results and identify statistically significant trends in the surface roughness and material removal rate data.

\subsection{Analysis for Surface Roughness}

Table 3 shows the experimental results and corresponding $\mathrm{S} / \mathrm{N}$ ratio for surface roughness $\left(\mathrm{R}_{\mathrm{a}}\right)$ using the relation for lower the better. Table 4 shows the analysis of mean (ANOM) for surface roughness. From Table 3, it is observed that optimized level for surface roughness is $A_{3} B_{1}$ and $\mathrm{C}_{2}$. Moreover, the depth of cut $(\mathrm{C})$ having the largest values of difference between maximum and minimum values among the three parameters. The main effects plots for surface roughness were constructed. As may be observed also from Figure 2 that the optimal combination of machining parameters is $A_{3} B_{1} C_{2}$ i.e. the minimum value of surface roughness is obtained at speed of $6000 \mathrm{rpm}$, feed rate of $500 \mathrm{~mm} /$ tooth and depth of cut of $0.06 \mathrm{~mm}$. ANOVA results for surface roughness are given in Table 5 . From Table 5 it can be noticed that the depth of cut has maximum influence on the $\mathrm{R}_{\mathrm{a}}$ with the contribution $71.60 \%$, followed by feed rate and cutting speed with contributions $23.22 \%$ and $2.12 \%$ respectively. In may be due to fact that the tool chip contact length increases with increasing depth of cut causing increase in the chip width leading to increase in the cutting forces and temperature which in turn effect on the surface roughness values. These results agree with previous studies [3, 14]. 
Table 3. Experimetal results and $\mathrm{S} / \mathrm{N}$ ratios values for surface roughness

\begin{tabular}{|c|c|c|c|c|c|c|}
\hline Expt. no. & $\mathrm{A}$ & $\mathrm{B}$ & $\mathrm{C}$ & $\mathrm{R}_{\mathrm{a}}(\mathrm{yi})$ & $\mathrm{S} / \mathrm{N}$ & $\mathrm{h} \wedge 2$ \\
\hline 1 & 2000 & 500 & 0.04 & 0.2535 & 11.92 & 142.097 \\
\hline 2 & 2000 & 1000 & 0.06 & 0.157 & 16.08 & 258.631 \\
\hline 3 & 2000 & 1500 & 0.08 & 0.243 & 12.29 & 150.992 \\
\hline 4 & 4000 & 500 & 0.08 & 0.201 & 15.65 & 244.923 \\
\hline 5 & 4000 & 1000 & 0.04 & 0.29 & 10.75 & 115.606 \\
\hline 6 & 4000 & 1500 & 0.06 & 0.206 & 13.72 & 188.311 \\
\hline 7 & 6000 & 500 & 0.06 & 0.152 & 16.36 & 267.752 \\
\hline 8 & 6000 & 1000 & 0.08 & 0.17 & 15.39 & 236.884 \\
\hline 9 & 6000 & 1500 & 0.04 & 0.299 & 10.49 & 109.968 \\
\hline Total & & & & & 122.66 & 1715.16 \\
\hline
\end{tabular}

Table 4. Analysis of mean (ANOM) for surface roughness

\begin{tabular}{|c|c|c|c|c|c|c|c|c|}
\hline Factor & Symbol & Unit & Level-1 & Level-2 & Level-3 & Max & Min & Max-Min \\
\hline speed & A & rpm & 13.43 & 13.37 & 14.08 & 14.08 & 13.37 & 0.71 \\
\hline feed rate & B & mm/tooth & 14.64 & 14.08 & 12.17 & 14.64 & 12.17 & 2.48 \\
\hline depth of cut & C & $\mathrm{mm}$ & 11.05 & 15.39 & 14.44 & 15.39 & 11.05 & 4.34 \\
\hline
\end{tabular}

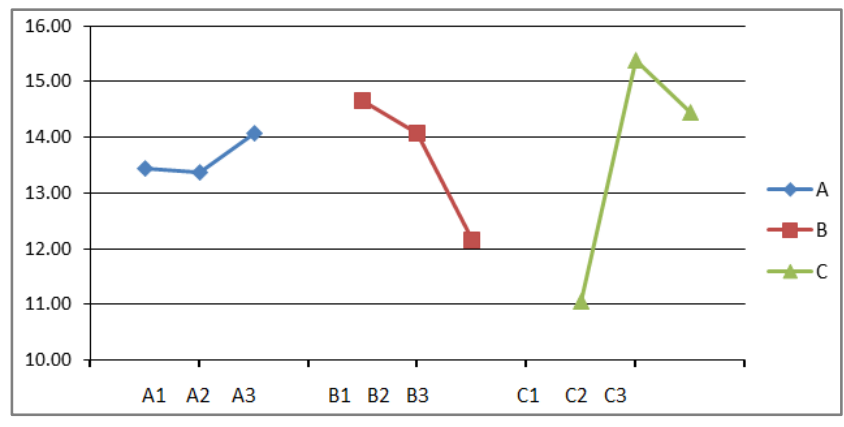

Figure 2. The main effect plot for $\mathrm{S} / \mathrm{N}$ ratio for Surface Roughness

Table 5. ANOVA results for surface roughness.

\begin{tabular}{|c|c|c|c|c|c|}
\hline Source & Sum of sequence & DF & Mean square & F ratio & \% Contribution \\
\hline A & 0.92 & 2 & 0.46 & 0.69 & 2.12 \\
\hline B & 10.11 & 2 & 5.06 & 7.59 & 23.22 \\
\hline C & 31.19 & 2 & 15.60 & 23.41 & 71.60 \\
\hline Error & 1.33 & 2 & 0.67 & & 3.06 \\
\hline Total & 43.56 & 8 & & & 100.00 \\
\hline
\end{tabular}

\subsection{Analysis for Material Removal Rate}

Experimental results of the material removal rate are shown in Table 6. The analysis of mean for MRR is shown in Table 7. It is observed from Table 7 that the feed rate having the highest values of difference between maximum and minimum among the three parameters. From above observation it is further concluded that feed rate being the highest value, is the most significant parameter for material removal rate. It can be derived also from Figure 3 that the optimal combination of machining parameters is $A_{1} B_{3} C_{3}$ i.e. the maximum value of MRR is obtained at $2000 \mathrm{rpm}$ of speed, $1500 \mathrm{~mm} /$ tooth of feed rate and $0.08 \mathrm{~mm}$ of depth of cut. ANOVA results for MRR are given in Table 8 . It can be seen from Table 8 that the feed rate has maximum influence on the MRR with the contribution $68.58 \%$, followed by depth of cut and machining speed with contributions $22.13 \%$ and $7.52 \%$ respectively. Since the feed rate is the speed of the cutting tool's movement relative to the workpiece as the tool makes a cut and the size removed of chip per tooth increases with increasing the feed rate. Therefore, the material removal rate increases significantly with increasing feed rate. 
Table 6. Experimetal results and $\mathrm{S} / \mathrm{N}$ ratios values for material removal rate

\begin{tabular}{|c|c|c|c|c|c|c|}
\hline Exp. no. & $\mathrm{A}(\mathrm{rpm})$ & $\mathrm{B}(\mathrm{mm} /$ tooth $)$ & $\mathrm{C}(\mathrm{mm})$ & $\mathrm{MRR}$ & $\mathrm{S} / \mathrm{N}$ & $\mathrm{h}^{\wedge} 2$ \\
\hline 1 & 2000 & 500 & 0.04 & 206.6890 & 46.31 & 2144.278 \\
\hline 2 & 2000 & 1000 & 0.06 & 615.52 & 55.78 & 3111.949 \\
\hline 3 & 2000 & 1500 & 0.08 & 1235.45 & 61.84 & 3823.753 \\
\hline 4 & 4000 & 500 & 0.08 & 233.46 & 47.36 & 2243.372 \\
\hline 5 & 4000 & 1000 & 0.04 & 236.34 & 47.47 & 2253.472 \\
\hline 6 & 4000 & 1500 & 0.06 & 927.29 & 59.34 & 3521.747 \\
\hline 7 & 6000 & 500 & 0.06 & 307.87 & 49.77 & 2476.789 \\
\hline 8 & 6000 & 1000 & 0.08 & 801.83 & 58.08 & 3373.478 \\
\hline 9 & 6000 & 1500 & 0.04 & 622.66 & 55.89 & 3123.135 \\
\hline Total & & & & 481.84 & 232170.8 \\
\hline
\end{tabular}

Table 7. Analysis of Mean (ANOM) for material removal rate

\begin{tabular}{|c|c|c|c|c|c|c|c|c|}
\hline Factor & Symbol & Unit & Level-1 & Level-2 & Level-3 & Max & Min & Max-Min \\
\hline Speed & A & rpm & 54.64 & 51.39 & 54.58 & 54.64 & 51.39 & 3.25 \\
\hline Feed rate & B & mm/tooth & 47.81 & 53.78 & 59.02 & 59.02 & 47.81 & 11.21 \\
\hline Depth of cut & C & $\mathrm{mm}$ & 49.89 & 54.97 & 55.76 & 55.76 & 49.89 & 5.87 \\
\hline
\end{tabular}

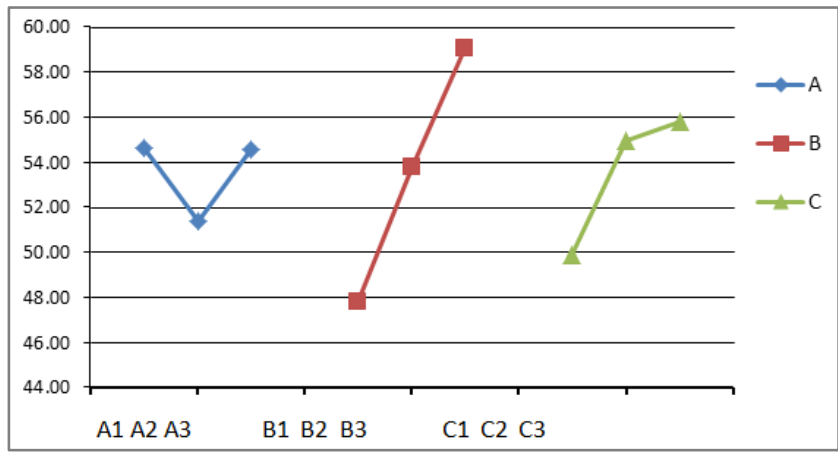

Figure 3. The main effect plot for $\mathrm{S} / \mathrm{N}$ ratio for material removal rate

Table 8. ANOVA results for material removal rate.

\begin{tabular}{|c|c|c|c|c|c|}
\hline Source & $\begin{array}{c}\text { Sum of } \\
\text { sequence }\end{array}$ & DF & $\begin{array}{c}\text { Mean } \\
\text { square }\end{array}$ & F ratio & $\begin{array}{c}\% \\
\text { Contribution }\end{array}$ \\
\hline A & 20.71 & 2 & 10.35 & 4.26 & 7.52 \\
\hline B & 188.73 & 2 & 94.37 & 38.81 & 68.58 \\
\hline C & 60.92 & 2 & 30.46 & 12.53 & 22.13 \\
\hline Error & 4.86 & 2 & 2.43 & & 1.77 \\
\hline Total & 275.22 & 8 & & & 100.00 \\
\hline
\end{tabular}

\section{Conclusions}

In this study, milling operations of complex shape on difficult to machine material i.e. copper were conducted. The effect of three machining parameters viz. speed, feed rate and depth of cut on the two response variables namely surface roughness and material removal rate were investigated. Taguchi's design i.e. $\mathrm{L}_{9}$ orthogonal array was used to obtain optimum machining parameters.
Subsequently, ANOVA was applied to investigate the effect of machining parameters on $\mathrm{R}_{\mathrm{a}}$ and MRR and to obtain the percentage distribution of the parameters. From the results of the present study the following conclusion are drawn: (i)The optimum combination of machining parameters and their levels for decreasing the deviation in $\mathrm{R}_{\mathrm{a}}$ and MRR are $\mathrm{A}_{3} \mathrm{~B}_{1} \mathrm{C}_{2}$ and $\mathrm{A}_{1} \mathrm{~B}_{3} \mathrm{C}_{3}$ respectively; (ii) depth of cut significantly affects $\mathrm{R}_{\mathrm{a}}$; the percentage contribution of depth of cut, feed rate and speed are $71.60 \%, 23.22 \%, 2.12 \%$ respectively;(iii)feed rate significantly affects MRR, the percentage contribution of feed rate, depth of cut and speed are $68.58 \%, 22.13 \%$ and $7.52 \%$ respectively.

\section{REFERENCES}

[1] M. Gupta, S. Kumar, Investigation of surface roughness and MRR for turning of UD-GFRP using PCA and Taguchi method Engineering Science and Technology, an International Journal Vol. 18 (2015), p.70-81.

[2] T. Kivak: Measurement Vol.50 (2014), p.19-28, Optimization of surface roughness and flank wear using the Taguchi method in milling of Hadfield steel with PVD and CVD coated inserts. Measurement, Vol. 50, pp. 19-28, 2014.

[3] N. Mandal, B. Doloi, B. Mondal: Predictive modeling of surface roughness in high speed machining of AISI 4340 steel using yttria stabilized zirconia toughened alumina turning insert, Int. Journal of Refractory Metals and Hard Materials Vol.38, p.40-46, 2013

[4] K. Palanikumar, Application of Taguchi and response surface methodologies for surface roughness in machining glass fiber reinforced plastics by PCD tooling, International Journal for Advanced Manufacturing Technology, Vol.36 19-27, 2008. 
[5] G. Petropoulos, F. Mata, J. P. Davim, Statistical study of surface roughness in turning of peek composites, Materials and Design Vol.29 p.218-223, 2008.

[6] R. Suresh, S. Basavarajappa, V. N. Gaitonde, G. L. Samuel: Machinability investigations on hardened AISI 4340 steel using coated carbide insert, Int. Journal of Refractory Metals and Hard Materials 33, p.75-86, 2012.

[7] R. Dhabale, V. K. S. Jattib, T. P. Singh, Multi-Objective Optimization of Turning Process during Machining of AlMg1SiCu Using Non-Dominated Sorted Genetic Algorithm, Procedia Materials Science, Vol.6, p.961-966, 2014.

[8] A. Molina, A. Torres-Islas, S. Serna, M. Acosta-Flores, R.A. Rodriguez-Diaz, J. Colin, Corrosion, Electrical and Mechanical Performance of Copper Matrix Composites Produced by Mechanical Alloying and Consolidation Int. J. Electrochem. Sci. Vol.10, p.1728- 1741, 2015.

[9] I. Asilturk, H. Akkus, Determining the effect of cutting parameters on surface roughness in hard turning using the
Taguchi method, Measurement Vol.44, p.1697-1704, 2011.

[10] O. Koksoy, Z. F. Muluk, Solution to the Taguchi's problem with correlated responses, Gazi Univ. J. Sci. Vol.17, No.1, p. 59-70, 2004.

[11] S.H. Park: Robust design and analysis for quality engineering, Chapman \& Hall, London1996.

[12] A. Hamdan, A. A. D. Sarhan, M. Hamdi: An optimization method of the machining parameters in high-speed machining of stainless steel using coated carbide tool for best surface finish, Int J Adv Manuf Technol, Vol.58, p.81-91, 2012.

[13] N. Masmiati A,B, Ahmed A.D. Sarhan, Optimizing cutting parameters in inclined end milling for minimum surface residual stress-Taguchi approach, Measurement, Vol.60, 267-275, 2015.

[14] N. Mandal, B. Doloi, B. Mondal: Force prediction model of zirconia toughened alumina (ZTA) inserts in hard turning of AISI 4340 steel using response surface methodology, Int J Precision Eng and Manuf, Vol.13, p.1589-99, 2012. 